\title{
How Does Agroecology Contribute to the Transitions towards Social-Ecological Sustainability?
}

\author{
Elisa Oteros-Rozas ${ }^{1,2}{ }^{-}$, Federica Ravera ${ }^{1,2}$ and Marina García-Llorente ${ }^{1,3,4, *}$ \\ 1 FRACTAL Collective, San Remigio 2, 28022 Madrid, Spain \\ 2 Chair on Agroecology and Food Systems, University of Vic-Central University of Catalonia (UVic-UCC), C. \\ de la Laura, 13, 08500 Vic, Spain \\ 3 Social-Ecological Systems Laboratory, Department of Ecology, Universidad Autónoma de Madrid, 28049 \\ Madrid, Spain \\ 4 Department of Applied Research and Agricultural Extension, Madrid Institute for Rural, Agricultural and \\ Food Research and Development (IMIDRA), Ctra. Madrid-Barcelona (N-II) KM. 38.200, \\ 28802 Alcalá de Henares, Spain \\ * Correspondence: marina.gllorente@uam.es
}

Received: 6 August 2019; Accepted: 7 August 2019; Published: 13 August 2019

\begin{abstract}
This Special Issue of Sustainability aims at compiling original theoretical, methodological, and empirical research exploring how agroecology approaches can promote the transition towards sustainability, particularly of agri-food social-ecological systems, taking into account the complex relationships established between ecological functions and ecosystem services, human wellbeing, innovative socio-technical innovations, and governance models as well as public policies. In this editorial, we carry out an overview of the 17 contributions that shape this number, around five main themes: Agroecological practices that enhance ecosystem services, the potential of agroecology to promote social learning and innovation, gender and feminist perspectives in agroecology, the political articulation of agroecology, and public policies and the institutionalization of agroecology. Finally, we reflect about suggested guidelines for agroecology research that truly aims at supporting the transition towards strong social-ecological sustainability, we then deepen on the main gaps revealed by the research works presented. Finally, we conclude with the insights provided by agroecology within the transition towards social-ecological sustainability.
\end{abstract}

Keywords: agroecosystem; ecosystem service; food sovereignty; gender; local agroecological knowledge; participatory approach; public policies; social-ecological system; social and inclusive farming; social learning

\section{Rationale: Why Do We Need Agroecology for the Transition towards Sustainability?}

Academics, practitioners, and activists have been discussing in recent decades how an increasing population can be fed in a social-ecologically sustainable and equitable way [1]. Despite the scientific and technological achievements to improve agricultural productivity, insufficient attention has been paid to the environmental and social consequences of the current dominant agri-food system models [2]. The current globalized and capitalist agri-food system has industrialized agriculture, displaced people from rural areas, polluted soils and water bodies, pushed the loss of biodiversity to an unprecedented situation, and still failed to end hunger [3,4]. This progressive intensification negatively impacts on agricultural landscapes and key ecological processes and ecosystem services [5], increasing agroecosystems' vulnerability and generating ecosystem disservices [6]. Agroecology is a scientific discipline, a set of practices, and a socio-political movement that respond to those impacts [7]. It applies ecological concepts in the sustainable management of agri-food systems [8,9]: agroecology mimics 
natural processes in order to minimize external inputs and help foster regenerative ways of producing food with nature, while generating social, cultural, and economic richness under sustainability principles [10]. As a socio-ecological approach, agroecology requires holistic and interdisciplinary views to analyze the complex relationships that are generated between ecological functioning, human wellbeing, innovative socio-technical innovations, governance models, and land-use policies. Overall, agroecology has a transformative character that implies the redesign of the entire agri-food system [11].

In the last decade, agroecology has become increasingly central to global agrarian social movements, mainly led by La Via Campesina and their claim for a transformation of policies and practices towards food sovereignty, i.e., the right of those who produce, distribute, and consume food to access and control the resources, mechanisms, decision-making, and policies that shape the food system [12]. The Food and Agriculture Organization (FAO) has also started an initiative called "Scaling up Agroecology" with the idea to study the potential of agroecology to contribute to the 2030 agenda and the Sustainable Development Goals (SDGs), considering three main areas of work: (1) knowledge and innovation for sustainable food and agricultural systems (through scientific evidence and local experiences), (2) policy processes for transformation of food and agricultural systems, (3) building social and institutional connections for transformative change to promote dialogue and collaboration between agents [13]. Despite such recognition, to date, agroecology has not gained enough strength as a scientific discipline and its application in agrarian, rural, and landscape planning and food policies is still limited [14].

For this Special Issue we invited scientific contributions to explore how agroecological approaches can contribute to the transition towards social-ecological sustainability. Specifically, we called for both conceptual and empirical studies that analyzed how agroecological initiatives contribute to global and climate change adaptation and mitigation, including community-supported agriculture models; social and inclusive farming; agroecosystem services assessments; agroecological rural development; the role of local, traditional, and indigenous agroecological knowledge and its transmission; agroecological public policies; participatory-action research processes; and gender and rural perspectives.

In this editorial, we perform an overview of the 17 contributions that shape this special issue, around five main themes: Agroecological practices that enhance ecosystem services, the potential of agroecology to promote social learning and innovation, gender and feminist perspectives in agroecology, the political articulation of agroecology and public policies and the institutionalization of agroecology. In the last section, we reflect about suggested guidelines for agroecology research that truly aims at supporting the transition towards strong social-ecological sustainability, we then deepen on the main gaps revealed by the research works presented. Finally, we conclude with the insights provided by agroecology within the transition towards social-ecological sustainability.

\section{Overview of Contributions}

The geographical distribution of the contributions covers an international representation, with nine studies from Europe, including Spain, UK, and France; six studies from the Americas (Canada, United States, Brazil, and Peru); and Africa, with one study from Zimbabwe. The scale of the studies primarily involves local or regional cases, with few cases addressing a national context and a review with an international scope. While most studies focus primarily on agriculture, a representation of other sectors, such as pastoralism, is also included, however with others missing such as fishery.

In terms of the agri-food system, most contributions to this Special Issue look at the production stage. Some studies focus on commercialization through the study of short food supply chains and consumption, analyzing participatory guarantee systems and nutritional habits in relation to organic food. Regarding the topics covered, agroecological practices are analyzed in eight studies, seven studies cover aspects related to social learning and innovation, five include gender and feminist perspectives in agroecological research, and seven deal with the socio-political articulation of agroecology. Finally, five cases are mainly related to the implementation of agroecology in public policies.

The theoretical approaches adopted are diverse, in line with the holistic and polysemic nature of agroecology, including political economy, food sovereignty, resilience, ecosystem services, traditional 
agroecological knowledge, system thinking, gender perspectives, social-ecological systems, among others. Most of the studies are empirical and involve place-based research with a diverse branch of methods for data gathering, including surveys, interviews, participatory workshops, and content analysis, sometimes within participatory action research processes and/or incorporating innovative methods such as filmmaking.

\section{Emerging Arenas of Research in Agroecology}

\subsection{Agroecological Practices}

One of the key dimensions that defines agroecology is applying the principles of ecological functioning to the design and management of farming [11]. Therefore, agroecological practices aim to enhance biodiversity and ecosystem services, conserving agricultural landscapes' complexity and multi-functionality while producing food. However, agroecology is not only about the production system and its environmental sustainability, but it also implies practices within the whole food system, including transformation, transport, commercialization, and consumption, culturally appropriate and driven from producer to consumer in a socially fair and accessible way [15].

Regarding the production system, agroecological farming practices are promoted by diverse farming models, such as conservation agriculture, permaculture, ecological intensive agriculture, biodiversity-based agriculture, biodynamic farming, and diversified agriculture. All these options share an ecosystem-based orientation, and they aim at promoting biodiversity through a diverse range of practices, such as the use of vegetation cover by no-tillage practices or cover crops, the enhancement of agrobiodiversity through the use of local landraces, the enrichment or conservation of soil organic matter and soil biotic activity through the addition of compost and the non-use of chemical inputs (fertilizers, pesticides, herbicides), the recycling of nutrients integrating livestock and agriculture, or the promotion of pollination and pest regulation by attracting wild and domestic pollinators [16-18]. To genuinely promote the agroecological transition towards sustainability, it is crucial to transcend exceptional farming situations. To achieve this, it is important to provide rigorous and sufficient scientific evidence that assesses how agroecological practices can enhance the supply of ecosystem services by agroecosystems. So far, agroecological practices have proven to be more effective than conventional practices in supplying a wide variety of ecosystem services (Contribution 1).

Criteria and indicators for ecosystem services provision and economic sustainability should be identified and assessed in order to evaluate the impacts of agroecological practices. For instance, potential environmental benefits derived from the sustainable use and management of manure as organic fertilizer and from animal feeding based on the sustainable use of pastures, usually neglected in conventional analyses, have been assessed in terms of energy efficiency (Contribution 2). A new synthetic indicator is suggested, which includes, among others, the cost avoided by using goat manure as a central element of the nutrients flow within the agroecosystem instead of conventional fertilizers.

At a farm level, there are some practices that are easily applicable, such as the replacement of agrochemicals by organic fertilization, which implies a technological change, or the use of cover crops or crop diversification, which are more integrated into modern agriculture. Intercropping, use of manure, family collaboration, and use of landrace seeds, for instance, are technical improvements at farm level (Contribution 3). Other practices can only be successful when applied through changes at the landscape level, such as the diversification of landscapes, which facilitates pollination, improves soil fertility, and increases water flow services. These practices entail working at a landscape scale and require agreement and collective thinking and action among different stakeholders [19]. Therefore, at this scale, agroecological transitions require not only technological innovations but also the mobilization of farmers, their cooperation, and new governance structures [20]. From a cultural perspective, social capital, including peasant knowledge, group participation, and gender equity, are key features (Contribution 3). Certain agroecological practices are based on technical improvements, but others require an advantageous socio-political setting. For instance, the engagement in networks with social 
organizations, universities, local culture, public policies, etc. are distinctive features of agroecological farms, reinforcing the idea that agroecology needs to be defined by technical changes but also by institutional ones (Contribution 3) and by new forms of learning and knowledge production, such as the documentation of traditional and local ecological knowledge (Contribution 4, see Section 3.2).

Improving farmers' knowledge on the interaction between ecosystem components and among different ecosystem services is important but not sufficient if they do not participate in cooperative solutions (Contribution 5). However, landscape-scale coordination and cooperative strategies for pest control in apple orchards in France was shown to be hindered by famers' little consideration of the interdependence between their practices and the landscape and their limited perception of the landscape as an ecosystem service provider (Contribution 5). Providing farmers with practical evidence of how agroecological practices influence ecosystem functioning has proven indeed to be a key to fostering agroecological transitions, as suggested in the creative and innovative initiative of the living lab of Agrolab in Madrid (Spain; Contribution 6).

From the consumption side, economic and cultural challenges are currently debated within agroecology: Consumers' motivations to adopt agroecological practices-from buying to cooking (Contribution 7), conventionalization of consumption through mainstream channels [21], and producer-consumer relationships [22] are some of the topics. In particular, the strategies implemented by consumers to overcome the perceived limitations to "eating well" differ across social profiles but largely relate to feminine and rural spaces, which are however largely disregarded (Contribution 7). Scarce purchase power or awareness, for instance, are overcome by changes not only at individual scale, e.g., in consumption habits, values or skills, but also through collective socialization dynamics and the complementary nature of access channels, therefore also challenging class assumptions. However, as in the farming perspective, deeper cultural changes are needed. These include truly incorporating feminist approaches in everyday practices in order to address the key limitation, as expressed by consumers, of time availability to assume more sustainable consumption habits (Contribution 7).

In between producers and consumers, commercialization plays a critical role for the economic and environmental sustainability of agri-food systems. Agroecology advocates for minimizing the social, economic, and geographical distance between producers and consumers through initiatives such as short food supply chains. These initiatives can be game-changers against the standardization of food and in favor of food sovereignty, particularly in peri-urban areas, minimizing the social, economic, and geographical distance between consumers and producers (Contribution 8). Box schemes, community-supported agriculture, green procurement, and public provision of food and producers' markets are some of these initiatives in which decentralized cooperation, social capital, and governance are key elements for creating closer and more stable relations between consumers and producers and improving producers' economic turnout (Contribution 8).

\subsection{Social Learning and Innovations}

Agroecology is an alternative development paradigm that endorses a rupture also in conventional thinking of food and agricultural systems [23,24]. Agroecological transformations imply a profound change in learning and knowledge exchange processes as key to supporting the dissemination and scaling of lessons, as suggested both by social movements [25] and mainstream institutions [13]. Therefore, agroecological transformations require the seeding of innovative strategies and practices, institutional arrangements, and the hybridization of epistemological domains, such as scientific knowledge and traditional agroecological knowledge, from farm-to-fork, that genuinely changes beliefs and behaviors (Contribution 9).

Approaches to learning and knowledge production and exchange should be transformative by challenging paradigms and worldviews and opening epistemological dialogues, based on horizontal training, peer-to-peer formats, diálogo de saberes, combination of practical and political knowledge [26], and intergenerational learning. Agroecology also entails a paradigm shift in training: from reductionist perspectives to integrated and holistic/systemic thinking, for instance in grazing practices that 
are adaptive, combining lessons on day-to-day skills and concepts with shifts in understanding (Contribution 10).

Implementing transformative learning approaches requires novel methodologies, such as new forms of communication and networks of articulation that seek to raise critical consciousness, people's empowerment, and political action. In this sense, both governmental and research institutions as well as social movements and networks promote on-farm experiments, participatory research, and peasant-to-peasant learning exchange (Contribution 3). An example of this is the abovementioned living lab Agrolab in Madrid (Spain; Contribution 6) that has reactivated the agrarian sector in rural and periurban areas. In this case, applying a social-ecological system thinking and enhancing participation, social inclusion, circular economy, and a combination of knowledge systems, have demonstrated to be interesting steps in such a transformative learning approach. Another example of novel methodologies for knowledge production is the digital platform CONECT-e, an innovative way of documentation, storing and sharing traditional ecological knowledge engaging farmers (Contribution 4). It allows sharing traditional ecological knowledge, such as vernacular names, description, use and management of landraces (including the adequate time of sowing), potential pests, adaptation to different contexts, etc. In the current setting of global environmental crisis, the accessibility of this information to both traditional farmers and new peasants can contribute to the maintenance of landraces and their potential for adaptation, and therefore facilitate the agroecological transition. Through this online collaborative inventory, knowledge is interpreted as a digital common, and misappropriation and enclosure processes are avoided (Contribution 4). A step further is given when social movements implement action research through arts-based sustainability methods, such as ethno-videography (Contribution 11), based on the pedagogy of Freire, to engage youth in a process of re-signification of agroecology, by revalorizing peasant knowledge and values.

As suggested by the food sovereignty movement, horizontality, and peer-to-peer support-campesino a campesino-in training and learning processes, based on popular education, should be transformative in politics and practices [25]. For instance, spaces of collaboration and training through social farming that promote relationships between farmers and with nature are analyzed in Zimbabwe in a peacebuilding process (Contribution 12). They promote interpersonal relationships between farmers and with nature, gradually transforming a culture of control towards a culture of recognition of plural ways of knowing and doing (see Section 3.4).

\subsection{Intersectional Feminist Perspectives}

Five out of the 17 contributions in this Special Issue consider the topic of gender in some way, basically around: (1) the gendered motivations for adopting agroecological practices or training, (2) the implications of the gendered division of labor inside and outside the household, and (3) the role that women and feminist collective action might play for the advancement of agroecology.

Different studies reveal gendered motivations in enrolling in training and learning processes. In adaptive grazing training, women's involvement was related to motivations around health and quality of life, whereas men seemed to be more interested in profitability and production (Contribution 10). In the agroecology living lab Agrolab, men were more interested in learning and promoting organic farming and instilling traditional knowledge and practices, while women showed higher interest in obtaining quality food products, being in contact with natural landscapes, and transmitting family values (Contribution 6).

With regards to the gendered distribution of work, in Peru it is mainly women in the farm who are responsible for the commercialization process, which explains why more women are involved in participatory guarantee systems (Contribution 13). In Spain, instead, the gendered division of household labor entails that women are more closely involved in food buying and preparation, so their lack of time due to double or triple work load (waged job, unpaid household labor, and eventually social action) seems to be one of the main limitations to increasing organic food consumption (Contribution 7). Instead of reorganizing the division of tasks and democratizing care activities, such as those related to 
food (thinking what to cook, distributing the available budget, satisfying family tastes, preserving food, cooking in advance, deciding when and where to shop, etc.), the industry is partly taking on some of them. The consequence is further cultural de-agrarization and societal detachment from the importance of these tasks of eating well, therefore hindering the agroecological transition (Contribution 7).

With regards to the role of women and feminism in agroecological transitions, it was observed that women's organization in feminist collectives seems to influence the awareness of young agroecologists in Brazil around gender issues, as well as about social diversity, racialism, or sexual identity (Contribution 11). Another example is that some trainers of adaptive grazing perceived that having a diverse mix of men and women contributed to bringing in a mix of ideas or keeping the men on track, and a women-only course resulted in a convivial atmosphere and strengthened relationships (Contribution 10). Some argue that this might be related to gender differences in performance of different tasks, risk perception, and risk assumption but also to the scale of analysis, i.e., whether it regards to individual or collective decision-making and action.

\subsection{The Political -Non Institutional- Articulation of Agroecology}

Even though there is an increasing influence of a "scientistic" or "technocratic" trend of agroecology, agroecosystems, as social-ecological constructs, are produced through power relations, and agroecology is inextricably linked with politics, as the devices responsible for the design and implementation of governance arrangements that make agri-food sustainability possible [15] and socially just. In fact, as already mentioned, agroecology is not only about farming practices and scientific and technical developments, but it is also a social movement, an element for inclusiveness, and a political tool ([27]; Contribution 14). Within the food sovereignty movement, organizations of food producers at local, regional, and national levels have embraced the ideals of agroecology (Contributions 8 and 14), and food movements around the world link agroecology to struggles for food sovereignty [28]. In Canada, for instance, as in many other regions of the world, agroecology entered the discourse of food movements via the food sovereignty movement (Contribution 14). Fostering networking and alliances (between farmers and non-farmers and between urban and rural stakeholders and food justice organizations), training, seed security, or participatory guarantee systems are among the activities in which agroecology civil society organizations and social movements engage, both in urban and rural areas (Contributions 8 and 13). For its conceptual structuring and political articulation, the agroecology movement relates to other social movements, such as those of solidarity economy (Contribution 8) and feminism (Contribution 7), highlighting the centrality of territorial, identity-based, and care approaches for the restructuring of the agri-food system as a whole, considering economic, environmental, social, cultural, and ethical aspects. In "violent environments", such as the study area in Zimbabwe, where the atmosphere and related management practices can be an arena within which conflicts play out at the local community level, agroecology and peacebuilding have proven to be mutually reinforcing-positive peaceful relations based on reciprocity, solidarity, and trust can be reforged between agroecological communities working together across the landscape (Contribution 12). In Spain, novel gastronomic movements have also been identified as drivers of agroecological initiatives (Contribution 9).

Scale plays a role also in both the articulation of agroecological initiatives and in their potential for large-scale transformation. For instance, networks supporting the establishment of agroecological initiatives in Spain are frequently of local nature, while those that contribute to their consolidation are umbrellas for several similar initiatives (Contribution 9). The potential and limitations of agroecological initiatives of different natures to expand and therefore substantially challenge the current mainstream agri-food system is a current vibrant debate in agroecology. Scaling strategies in agroecology, as in sustainability transitions, have been classified in three types ([29] in Contribution 9): Scaling deep (changing values and minds), scaling out (expanding impacts or replicating), and scaling up (changing rules, norms, and legislation). 
Despite the need to expand the concept, it is also important to be aware of the risk of the term "agroecology" to be co-opted or assimilated with large-scale monocultures of organic food, or with proposals as those of "climate-smart agriculture" and "sustainable intensification" [25]. To counter the risk of co-optation, some groups have even begun to specify that they are advocating for an explicitly "political agroecology" [15] or "political peasant agroecology" [30], explicitly questioning unequal power relations in the food system. This means that for agroecology to achieve the political, environmental, and socioeconomic transformations envisioned by the different stakeholders, popular pressure to change public policies and approaches to agri-food system is critical (Contribution 14; see Section 3.5). Additionally, top-down agroecological initiatives set-up by NGOs, such as participatory guarantee systems in Peru, pose challenges such as dependence on external funding resources, lack of producers' or consumers' commitment, or risk of centralization (Contribution 13).

\subsection{Public Policies for Agroecology}

The convergence of social pressure and political determination have driven the increasing institutionalization of agroecology and its integration in public policies at different scales with the aim of supporting a democratic control of agri-food systems. Particularly since 2015's Declaration of the International Forum for Agroecology in Nyéléni (Mali), which expresses and formalizes citizens' concerns and aspirations to impact public policies, the food sovereignty movement has devoted significant energies to this endeavor. Entry points to analyze agri-food public policies and their contributions to agroecology and social-ecological sustainability are: Which are their origins; how is agroecology conceptualized; who plays relevant roles in setting them and in further scaling them up; how are they applied in practice; or how do they contribute to transform individuals, communities, society, and ecosystems.

Some examples of these food policies range from fostering local development based on agroecological production to public purchases of agroecological food for state school or hospital canteens (e.g., the National School Meal Program-PNAE, and the Food Procurement Program-PAA, in Brazil; Contribution 15), fitting agroecology in existing agro-environmental measures (e.g., the EU Common Agricultural Policy, Contribution 16) or city-regions' food systems (e.g., Milan Urban Food Policy Pact, which was launched in October 2015 and signed by 117 mayors from all over the world (http://www.foodpolicymilano.org/urban-food-policy-pact/) [31,32]), or the establishment and support of peasant markets [33]. However, there is still scarce literature analyzing how the concept changes through the "translation" process of agroecology into policy instruments (Contribution 16).

At the same time, there is a concern about the risk that agroecology will be co-opted, institutionalized, colonized, and stripped of its political content [34] by corporations, experts, or public authorities [9]. Along this line, two approaches, currently in action in the EU setting, are mentioned in Contribution 16. The first approach refers to the conceptualization of agroecology in the UK only as a technified approach that reduces it to a set of practices [15]. The consequence of such an approach is the disregard and therefore lack of in-depth transformation of the power relations and inequities between actors within the agri-food system, i.e., de-politicizing agroecology. Contribution 14 explains how in Canada, for instance, there are policies that may support conservation, climate change mitigation, or organic production but do not seem to be covering the full scope of agroecology's multiple dimensions. The second approach refers to the monetary valorization of ecosystem services, like the agroecological project set up by the French Government, or the establishment of payments for ecosystem services schemes proposed by the UK Government in the post-Brexit scene, to address some environmental deadlocks resulting from a model of agriculture based on short-term profits (Contribution 16). These examples show how at a state level, understanding the intertwining of agri-food policies with economic policies appears to be critical in assessing the potential of these attempts of agroecological transformation for deep change. At lower scales, the cooperation between regional and local public policies to set up, dynamize, and monitor the agroecological living lab Agrolab in Madrid have shown how hybrid governance models that integrate public administrations 
at different scales and a research institute can promote dialogue and facilitate shared visions and innovative solutions (Contribution 6).

Agroecology also plays a pivotal role in current development policies. Despite the urgency of a transformative approach needed in agrarian development, very reduced funding have been to date allocated to projects with an explicit focus on development or promotion of agroecological innovations and practices (Contribution 17). In order to coherently meet the SDGs and specifically to respond to the interrelated challenges of malnutrition, poverty, ecological degradation, and other anthropogenic climate change challenges, governmental policies urgently require a re-prioritization of overseas aid in favor of large-scale agroecological transformation (Contribution 17). Finally, a clear need for critical public debate about how agroecology is being hybridized and translated within institutional boundaries, its risks, challenges, and potentials, as well as its impacts on the tripartite arena of agroecology emerges from the still scarce literature available. In fact, the articulation of claims pushed by the agroecology social movement in public policies and institutions entails a set of tensions between stakeholders [35].

\section{Final Reflections}

\subsection{Insights for Further Research for the Transition towards Sustainability}

Based on the findings from the contributions of the present Special Issue, we believe that agroecological research that truly aims at supporting the transition towards strong social-ecological sustainability should:

(1) Assess not only the impacts of farming practices in ecosystem functioning but also the social, economic, and cognitive dimensions of agri-food systems as social-ecological systems;

(2) Provide rigorous and relevant knowledge that can contribute to the iterative monitoring and evaluation of agroecological transitions and thus inform public debates and policies;

(3) Generate a collective understanding of agroecology, encourage and engage in multi-actor discussions about the benefits on (agro)biodiversity and ecosystem services associated with agroecological practices;

(4) Re-value local, traditional, and indigenous forms of knowledge, not from a nostalgic perspective, but for innovation and forward-looking;

(5) Generate collaborative spaces and hybrid governance systems where farmer-led research or more comprehensive farmer-research collaborations can occur, interpersonal relationships may be (re)forged, even in peacebuilding contexts, and different forms of knowing and doing can dialogue in equal conditions;

(6) Favor multi-scale approaches from individual to landscape scale when dealing with farming practices, to socialization of food consumption practices, and up to national and international scales when addressing public policies;

(7) Consider innovations in methodological approaches, including artistic tools, e-tools, and novel and inclusive action-research methods;

(8) Incorporate uncertainty about social-ecological dynamics so that decision-making and management can be adaptive;

(9) Engage, using a critical pedagogy, other social groups (e.g., young people, LGTB+) in re-signifying rural and agroecology;

(10) Translate agroecology in public policies, scaling bottom-up lessons from initiatives, favoring alliances within novel food governance systems, and avoiding a co-optation and de-politization of agroecological principles;

(11) Adopt a feminist intersectional perspective in agroecological research, considering the role of multiple identities (e.g., age, social status, ethnicity), which influence power dynamics 
and socio-demographic and cultural factors, such as poverty or gender inequities, in agroecological transitions.

\subsection{Major Gaps and Limitations in Agroecology Research}

From the reflections of the contributions of this special issue, we identified certain gaps and limitations with regard to the five main themes of reflection.

In terms of agroecological practices that enhance ecosystem services, the authors identified gaps related to a lack of knowledge and scientific evidence, the need for collective action and farmer networks, and the lack of support or incentives to those farmers that deliver public environmental services. Diverse contributions converge in highlighting that the dissemination of technical knowledge is still limited. They also show that robust scientific evidence and indicators to measure agroecological transitions and to compare different farming systems are still needed. Other types of gaps have been identified in relation with social innovation and learning. It is still unclear how mental paradigms and system thinking, such as individualistic mindsets, affect the adoption of sustainable farming practices. Future research is needed on how training may support changes in mental models and worldviews as a key step for adopting transformative practices.

We would also like to remark the need for further research to apply an intersectional feminist perspective in agroecological research. That "there is no agroecology without feminism" is a rising claim by women within the agroecology and food sovereignty movement, particularly in Latin America [36]. Women play and have historically played key roles across the whole agri-food system, from the land to the plate, and in the social struggle for agroecology [37]. However, these roles are still largely invisible, and gender and feminist perspectives in agroecological academic research are also still scarce in comparison to the momentum that the topic is gaining. An example is that only five out of the 17 contributions in this Special Issue consider the topic of gender. Further research with intersectional feminist perspectives is clearly needed in agroecology in order to better understand gender dimensions, as well as the intersections with other forms of power. The role of gender, class, racialism, age, and other axes of social discrimination should be explored to respond to different questions such the following. How are decisions around agri-food practices at all scales-from the farm to shaping public policies-gendered? How does the division of labor influence agri-food systems? How does de-agrarization and rural abandonment affect women, indigenous and racialized people, peasants, landless, and less-favored classes? How can inclusiveness and participation of specific sectors of the society be enhanced, particularly through collective action? How can inclusive spaces and forms or organization within the agroecological movement be further fostered?

In particular, regarding policy articulation, it has been recognized that power relationships and asymmetries in agri-food systems influence the way agroecology is translated into policies. Agroecology means to confront the political economic reality of our current system. At the same time, to guarantee the permanence of innovative initiatives, it is key to reinforce policies and fix institutional arrangements to guarantee the establishment of initiatives. Still, there is a lack of public policies' support or absence of legal recognition, for example of participatory guarantee systems or community-supported agriculture.

\section{Conclusions}

As shown, agroecology is a surprisingly heterogeneous, multi-scale, and multi-dimensional concept, which limits its scaling potential but at the same time facilitates space for transdisciplinary and multi-actor dialogues. Differences in framing agroecology in the societal debate confirm the need for democratic discussions on its conceptualization and implicit political choices at different scales. It has been recognized that power relationships and asymmetries in agri-food systems influence the way agroecology is translated into policies and practices. However, several contributions in the present Special Issue exemplify how public policies, particularly at state-level, should integrate practices, social movements, and science more effectively for agroecology to become a fundamental principle of agri-food systems. Even though international organizations for agriculture and food, such as FAO, 
have recognized agroecology as the only option to feed the world within planetary limits, agroecology is still absent or underrepresented in international public policies such as the Rural Development Policy of the EU Common Agricultural Policy. However, agroecology implies confronting the political and economic reality of the current agri-food system, so changes in policies and governance will most probably only be achieved through popular pressure by alliances between farmers and non-farmers and between urban and rural stakeholders, together with food justice organizations.

Within the transition towards social-ecological sustainability, agroecology principles and practices are providing insights in all three spheres: The environmental, the social, and the economic. From an environmental perspective, there is still a need to better understand the impacts of agroecological practices and particularly how landscape heterogeneity affects farm conditions. For some agroecological initiatives, the socio-economic dependence on external resources and the tendency to have donor-recipient, top-down structures can entail vulnerability. However, solidarity economy applied to food systems has shown great potential not only for the recovery and economic profitability of peri-urban small farmers and retailers but also for urban food transformation and restoration of rural-urban relationships. Additionally, different strategies exist to encourage a change in food consumption habits, to overcome financial barriers and promote collective socialization dynamics, supported by diverse and complementary channels, and contribute to fostering agroecological transitions. In any case, society needs further socio-economic research that can contribute to improving economic viability of agroecological food systems, from production to consumption, while transformative potential of agroecology maintains its independence from the market big players.

While it is true that still important barriers to the adoption of agroecological practices are social or community pressures to maintain the status quo, agroecology has also shown the potential to remember and re-story the past, present, and shape the future of communities; to re-signify peasantries and sociobiodiversity opening up spaces for women, racialized, indigenous, urban, and LGBT+ people; to gradually transform cultures towards recognition of plural ways of knowing and doing; and overall to co-produce interconnectedness between humans and nature.

\section{List of Contributions:}

1. Sara Palomo-Campesino, José A. González, Marina García-Llorente. Exploring the Connections between Agroecological Practices and Ecosystem Services: A Systematic Literature Review.

2. David Pérez Neira, Marta Soler Montiel, Rosario Gutiérrez Peña, Yolanda Mena Guerrero. Avoided energy costs and efficiency of pastoral dairy goat husbandry. A case study in Andalusia (Spain).

3. Heitor Mancini Teixeira, Leonardo van den Berg, Irene Maria Cardoso, Ardjan Vermue, Felix Bianchi, Marielos Peña-Claros, Pablo Tittonell. Understanding Farm Diversity to Promote Agroecological Transitions.

4. Laura Calvet-Mir, Petra Benyei, Laura Aceituno-Mata, Manuel Pardo-de-Santayana, Daniel López-García, María Carrascosa-García, Antonio Perdomo-Molina, Victoria Reyes-García. The Contribution of traditional agroecological knowledge as a digital commons to agroecological transitions: the case of the CONECT-e platform.

5. Nicolas Salliou, Roldan Muradian, Cécile Barnaud. Governance of ecosystem services in agroecology: when coordination is needed but difficult to achieve.

6. Marina García-Llorente, Irene Pérez-Ramírez, Clara Sabán de la Portilla, Carmen Haro, Alejandro Benito. Agroecological Strategies for Reactivating the Agrarian Sector: the Case of Agrolab in Madrid.

7. David Gallar Hernández, Helena Saracho-Domínguez, Marta G. Rivera-Ferré, Isabel Vara-Sánchez. Eating Well with Organic Food: Everyday (Non-Monetary) Strategies for a Change in Food Paradigms. Findings from Andalusia (Spain).

8. Carolina Yacamán Ochoa, Alberto Matarán, Rafael Mata Olmo, José María López, Rafael Fuentes-Guerra. The potential role of short food supply chains in strengthening periurban agriculture in Spain: the cases of Madrid and Barcelona.

9. Leonie Guerrero Lara, Laura M. Pereira, Federica Ravera, Amanda Jiménez-Aceituno. Flipping the Tortilla: Social-ecological innovations and traditional ecological knowledge for more sustainable agri-food systems in Spain.

10. Carolyn Mann, Kate Sherren. Holistic Management and adaptive grazing: A trainers' view.

11. Margriet Goris, Leonardo van den Berg, Ivonete da Silva Lopes, Jelle Behagel, Gerard Verschoor, Esther Turnhout. Resignification practices of youth in Zona da Mata, Brazil in the transition towards agroecology.

12. Georgina McAllister, Julia Wright. Agroecology as a practice-based tool for peacebuilding in fragile environments? Three stories from rural Zimbabwe. 
13. Nathalie Binder, Christian Reinhard Vogl. Participatory Guarantee Systems (PGS) in Peru: Two case studies in Lima and Apurimac and the role of capacity building in the food chain.

14. Isaac E. Marney, Ryan Isakson, Bryan Dale Charles Levkoe, Sarah Hargreaves, Ernesto Mendez, Hannah Wittman, Colleen Hammelman, Jennifer C. Langill, Adam Martin, Erin Nelson, Mike Ekers, Kira Borden, Stephanie Gagliardi, Serra Buchanan, Sarah Archibald, Astrid Galvez Ciani. Agroecology in Canada: Towards an Integration of Agroecological Practice, Movement and Science.

15. Antonio Gabriel Lima Resque, Emilie Coudel, Marie-Gabrielle Piketty, Nathalie Cialdella, Tatiana Sá, Marc Piraux, William Assis, Christophe Le Page. Can Institutional Markets Promote Agrobiodiversity and Ecosystem Services? Lessons from Two Federal Programs in the Eastern Brazilian Amazon.

16. Raquel Ajates Gonzalez, Jessica Thoma, Marina Chang. Translating agroecology into policy: the case of France and the UK.

17. Michel Pimbert, Nina Isabella Moeller. Absent Agroecology Aid: On UK agricultural development assistance since 2010.

Author Contributions: All authors contributed equally to this work. M.G.-L., E.O.-R. and F.R. conceptualized, wrote, and reviewed the work together.

Funding: E.O.R. was funded by the Juan de la Cierva Incorporation Fellowship of the Ministry of Science, Innovation and Universities (IJCI-2017-34334). F.R. was funded by the AXA Research Fund (2016). M.G.L. was funded by a postdoctoral grant from the Spanish National Institute for Agriculture and Food Research and Technology co-funded by the Social European Fund (Doc-INIA CCAA). This study also received funding from: AgroecologiCAM project funded by the European Union, the Spanish Ministry of Agriculture, Food and the Environment and Madrid Regional Government under the Rural Development Programme (RDP-CM 2014-2020) and from the European Union's Horizon 2020 research and innovation programme under grant agreement $\mathrm{N}^{\circ}$ 81819 , by the project entitled: Co-design of novel contract models for innovative agri-environmental-climate measures and for valorisation of environmental public goods.

Acknowledgments: We sincerely thank all the authors who contributed to this special issue. We thank the assistance provided by Crystal Cheng as contact editor. Finally, we thank all the reviewers who dedicated their time and effort to provide suggestions to improve the manuscripts.

Conflicts of Interest: The authors declare no conflict of interest.

\section{References}

1. Gliessman, S. Agroecology: A Growing Field. Agroecol. Sustain. Food Syst. 2015, 39, 1-2. [CrossRef]

2. McIntyre, B.D.; Herren, H.R.; Wakhungu, J.; Watson, R.T. IAASTD_International Assessment of Agricultural Knowledge, Science and Technology for Development: Global Report; Island Press: Washington, DC, USA, 2009.

3. Tilman, D. Global environmental impacts of agricultural expansion: The need for sustainable and efficient practices. Proc. Natl. Acad. Sci. USA 1999, 96, 5995-6000. [CrossRef] [PubMed]

4. FAO. The Future of Food and Agriculture: Trends and Challenges; Food and Agriculture Organization of the United Nations: Rome, Italy, 2017; ISBN 978-92-5-109551-5.

5. Swinton, S.M.; Lupi, F.; Robertson, G.P.; Hamilton, S.K. Ecosystem services and agriculture: Cultivating agricultural ecosystems for diverse benefits. Ecol. Econ. 2007, 64, 245-252. [CrossRef]

6. Zhang, W.; Ricketts, T.H.; Kremen, C.; Carney, K.; Swinton, S.M. Ecosystem services and dis-services to agriculture. Ecol. Econ. 2007, 64, 253-260. [CrossRef]

7. Anderson, C.; Pimbert, M.; Kiss, C.; Building, Defending and Strengthening Agroecology. A Global Struggle for Food Sovereignty. Available online: http://www.agroecologynow.com/wp-content/uploads/2015/05/ Farming-Matters-Agroecology-EN.pdf (accessed on 2 August 2019).

8. Altieri, M.A. Agroecology: The Science of Sustainable Agriculture, 2nd ed.; Westview Press: Boulder, CO, USA; London, UK, 1995; ISBN 978-0-8133-1718-2.

9. Wezel, A.; Bellon, S.; Doré, T.; Francis, C.; Vallod, D.; David, C. Agroecology as a science, a movement and a practice. A review. Agron. Sustain. Dev. 2009, 29, 503-515. [CrossRef]

10. Sevilla-Guzmán, E.; González de Molina, M. Ecología, Campesinado e Historia; La Piqueta: Málaga, Spain, 1993; ISBN 978-84-7731-146-1.

11. Gliessman, S.R. Agroecology: The Ecology of Sustainable Food Systems, 3rd ed.; CRC Press: Boca Raton, FL, USA, 2014; Available online: https://www.crcpress.com/Agroecology-The-Ecology-of-Sustainable-Food-SystemsThird-Edition/Gliessman/p/book/9781439895610 (accessed on 31 July 2019).

12. Martínez-Torres, M.E.; Rosset, P.M. La Vía Campesina: The birth and evolution of a transnational social movement. J. Peasant Stud. 2010, 37, 149-175. [CrossRef] 
13. FAO. Scaling up Agroecology Initiative. Transforming Food and Agricultural Systems in Support of the SDGs. A Proposal Prepared for the International Symposium on Agroecology 2018. Available online: http://www.fao.org/3/I9049EN/i9049en.pdf (accessed on 2 August 2019).

14. Sicili, L. Agroecology —What It Is and What It Has to Offer; IIED Issue Paper; IIED: London, UK, 2014; ISBN 978-1-78431-065-3. Available online: https://pubs.iied.org/pdfs/14629IIED.pdf (accessed on 2 August 2019).

15. González de Molina, M. Agroecology and Politics. How to Get Sustainability? About the Necessity for a Political Agroecology. Agroecol. Sustain. Food Syst. 2013, 37, 45-59.

16. Farley, J.; Schimitt Filho, A.; Alvez, J.; Ribero de Freitas, N., Jr. How Valuing Nature Can Transform Agriculture. Solutions 2012, 2, 64-73.

17. Gliessman, S. Transforming Food Systems to Sustainability with Agroecology. J. Sustain. Agric. 2011, 35, 823-825. [CrossRef]

18. Altieri, M.A.; Rosset, P. Agroecology and the conversion of lárge-scale conventional systems to sustainable management. Int. J. Environ. Stud. 1996, 50, 165-185. [CrossRef]

19. Stallman, H.R. Ecosystem services in agriculture: Determining suitability for provision by collective management. Ecol. Econ. 2011, 71, 131-139. [CrossRef]

20. Tittonell, P. Ecological intensification of agriculture-Sustainable by nature. Curr. Opin. Environ. Sustain. 2014, 8, 53-61. [CrossRef]

21. Constance, D.H.; Friedland, W.H.; Renard, M.C.; Rivera-Ferre, M.G. The Discourse on Alternative Agrifood Movements. In Alternative Agrifood Movements: Patterns of Convergence and Divergence; Research in Rural Sociology and Development; Emerald Group Publishing Limited: Bingley, UK, 2014; Volume 21, pp. 3-46.

22. Holloway, L.; Kneafsey, M.; Venn, L.; Cox, R.; Dowler, E.; Tuomainen, H. Possible Food Economies: A Methodological Framework for Exploring Food Production-Consumption Relationships. Sociol. Rural. 2007, 47, 1-19. [CrossRef]

23. Pimbert, M. Agroecology as an Alternative Vision to Conventional Development and Climate-smart Agriculture. Development 2015, 58, 286-298. [CrossRef]

24. Levidow, L.; Pimbert, M.; Vanloqueren, G. Agroecological Research: Conforming-Or Transforming the Dominant Agro-Food Regime? Agroecol. Sustain. Food Syst. 2014, 38, 1127-1155. [CrossRef]

25. Declaration of the International Forum for Agroecology, Nyéléni, Mali: 27 February 2015. Available online: http://www.foodsovereignty.org/wp-content/uploads/2015/02/Download-declaration-AgroecologyNyeleni-2015.pdf (accessed on 2 August 2019).

26. Anderson, C.R.; Maughan, C.; Pimbert, M.P. Transformative agroecology learning in Europe: Building consciousness, skills and collective capacity for food sovereignty. Agric. Hum. Values 2019, 36, 531-547. [CrossRef]

27. Méndez, V.E.; Bacon, C.M.; Cohen, R. Agroecology as a Transdisciplinary, Participatory, and Action-Oriented Approach. Agroecol. Sustain. Food Syst. 2013, 37, 3-18.

28. Rosset, P.M.; Altieri, M.A. Agroecology: Science and Politics; Agrarian Change and Peasant Studies: Little Books on Big Issues; Fernwood Publishing Co LTD: Black Point, NS, Canada, 2017.

29. Moore, M.L.; Riddell, D.; Vocisano, D. Scaling Out, Scaling Up, Scaling Deep: Strategies of Non-profits in Advancing Systemic Social Innovation. J. Corp. Citizsh. 2015, 2015, 67-84. [CrossRef]

30. Holt-Giménez, E.; Altieri, M. Agroecology, Food Sovereignty and the New Green Revolution. J. Sustain. Agric. 2012, 37, 90-102. [CrossRef]

31. Forster, T.; Egal, F.; Getz-Escudero, A.; Dubbeling, M.; Renting, H. Milan Urban Food Policy Pact. Selected Good Practices from Cities; Utopie 29, Globalizzazione; Fondazione Giangiacomo Feltrinelli: Milan, Italy, 2015.

32. Vaarst, M.; Gezt-Escudero, A.; Chappell, M.J.; Brinkley, C.; Nijbroek, R.; Arraes, N.A.M.; Andreasen, L.; Gattinger, A.; Almeida, G.F.D.; Bossio, D.; et al. Exploring the concept of agroecological food systems in a city-region context. Agroecol. Sustain. Food Syst. 2018, 42, 686-711. [CrossRef]

33. Nigh, R.; Cabañas, A.A.G. Reflexive Consumer Markets as Opportunities for New Peasant Farmers in Mexico and France: Constructing Food Sovereignty through Alternative Food Networks. Agroecol. Sustain. Food Syst. 2015, 39, 317-341. [CrossRef]

34. Giraldo, O.F.; Rosset, P.M. Agroecology as a territory in dispute: Between institutionality and social movements. J. Peasant Stud. 2018, 45, 545-564. [CrossRef]

35. López García, D.; Casadevante, J.L.F.; Morán, N.; Oteros-Rozas, E. Arraigar las Instituciones: Propuestas Políticas Agroecológicas Desde los Movimientos Sociales; Libros en Acción: Madrid, Spain, 2017; ISBN 978-84-946151-6-0. 
36. Siliprandi, E. Mujeres rurales en América Latina: organización y lucha campesina desde una perspectiva feminista. In Mujeres y Mundo Rural: Nuevos y Viejos Desafíos; Silipandri, E., Sabaté-Martínez, A., Senra-Rodríguez, L., Cruz, F., Eds.; FUHEM Ecosocial: Madrid, Spain, 2018.

37. Siliprandi, E.; Zuloaga, G.P. Género, Agroecología y Soberanía Alimentaria; Perspectivas Ecofeministas, Colección Perspectivas Agroecológicas; Icaria Editorial: Madrid, Spain, 2014.

(c)

(C) 2019 by the authors. Licensee MDPI, Basel, Switzerland. This article is an open access article distributed under the terms and conditions of the Creative Commons Attribution (CC BY) license (http://creativecommons.org/licenses/by/4.0/). 